\section{PSEUDO-HYPERTROPHIC MUSCULAR PARALYSIS.}

Read before the Indiana State Medical Soeiety, June, 1888. BY W. BYFORD RYAN, M.D., OF WILLOW BRANCH, IND.

I have the honor to present for your inspection three persons afflicted with this rare and imperfectly known disease.

The disease was first described by Sir Charles Bell in 1830 ; by two Italians, Coste and Gioja in I 838 ; by Meryon in I85 I. The disease did not, however, receive much attention until Duchenne (of Boulogne) reported his collection of thirteen cases in I868. The same year Dr. Meredith Clymer described the disease under the title "Progressive Myo-Sclerosic Paralysis," though he had not probably at that time seen a case. Dr. Clymer seems inclined to attribute the honor of discovery and first description of the disease to Dr. Edward Meryon, whose paper "On Granular and Fatty Degeneration of the Voluntary Muscles" was read December $9,185 \mathrm{I}$, and published in the Medico-Chirurgical Transactions, Vol. $\mathrm{xxxv}$, 1852 .

"Dr. Duchenne (de Boulogne), scouts the idea of Dr. Meryon having first described this affection (la priorité de la découverte). 'L'honneur de cette découverte appartient tout entière à la France" (that is, to himselt). In the same paper he says: "La découverte de la paralysie pseudohypertrophique remonte à l'année, I 858 ," the year he observed his first case. Thus, by his own dates he admits Meryon's priority in description.

Up to I 867 there were less than fifty recorded cases in the Old World and none on this side of the Atlantic. Subsequently Ingall and Webber, Pepper, Weir Mitchell, Hamilton, and others have reported cases. More recently Gowers, in a clinical lecture in London, I879, carefully reviewed the cases of English, Continental and American writers and compiled reports of one hundred and seventy-six cases. Of these all but eight were children. This seems to be the entire number on record to that date. I add four cases, three children and one adult.

It is not my purpose to enter into a verbose description of the disease, for excellent descriptions may be found in Clymer's Appendix to Aitken's Science and Practice of Medicine; in Ross's Diseases of the Nervous System; Pepper's and A. McL. Hamilton's works. Neither shall I attempt to solve the problem relative to the primary seat of the lesion, whether it be the muscles themselves, the anterior columns of the cord, or the anterior roots of the spinal nerves; but I shall confine myself to the history of the cases before us, presenting to you the characteristic appearance, attitude and pathognomonic actions of persons so afflicted, in a manner so definite that those I who see need have no difficulty in recognizing the disease if so unfortunate as to meet it in practice.

Dr. Duchenne details the symptoms of the disease in the following order:

I. In the beginning feebleness of the lower limbs. 2. Lateral balancing of the trunk and widening of the legs during walking. 3. A peculiar curvature of the spine or saddle-back in walking and standing ( $\mathrm{I}$ may add in sitting). 4. Talipes equinus with an over-extension of the first phalanges of the toes. 5. Apparent hypertrophy of muscles. 6. Stationary condition. 7. Generalization and aggravation of the paralysis.

These are the striking features of the disease as I have observed it; and I may add the 8 th, which is not, however, characteristic, atrophy of affected muscles.

The family to which these boys belong consist. ed of four boys and one girl. The eldest son, whom we have before us, is seventeen years old.

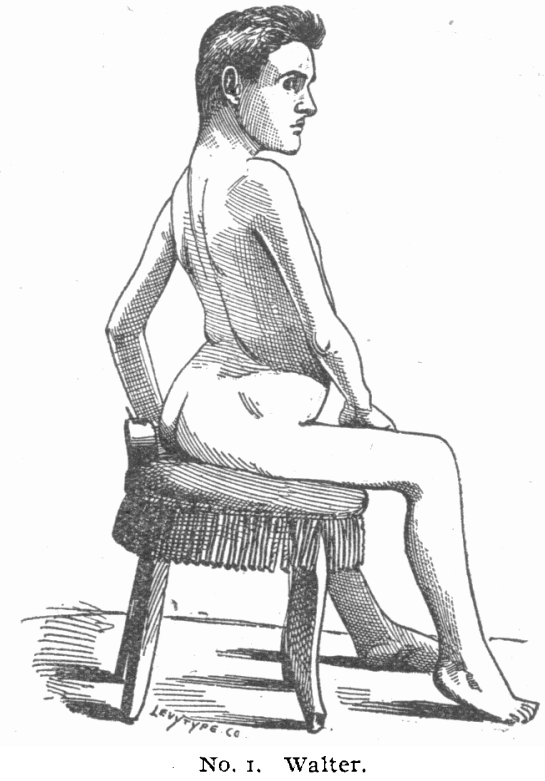

He began to walk at fifteen months, was a1ways awkward, and kept a very unstable equilibrium. He received many falls which an active child would have escaped, and many reprimands from his parents for being "lubberly" and inattentive, before they realized that all this came of weakness and partial paralysis.

His general health has always been excellent. Has never had pain in affected muscles, febrile symptoms, convulsions, or any prodromata. $\mathrm{He}$ was a well-formed child, and the hypertrophy of his calves was marked by all observers, and, to his friends, added to the symmetry of his limbs. His appetite was unusually keen, even for a growing boy, and, though vast quantities of excellent food and almost an equal amount of condiments and other "trash" was consumed between meals, 
his digestion never seemed to suffer. He was a gourmand, and still has an excellent appetite.

At nine years the sacro-lumbar curvature was very marked. This attitude is assumed because of weakness of the dorsal muscles and is essential to the maintenance of the erect posture.

The increasing cordosis led the family to call a prominent physician, a member of this Society, residing in an adjoining county, to consult with the gentleman who, up to this time, had been the family physician. I do not know what was the diagnosis. A plaster jacket was proposed, but for some reason never applied. T'reatment of beef, wine and iron, and of hypophosphites of lime and soda was given and persisted in for six months. No improvement followed, but, on the contrary, the disease progressed.

The patient, discouraged and disgusted with treatment of any kind, came under my care. After careful study, I diagnosed pseudo-hypertrophic muscular paralysis, and gave an unfavorable prognosis. At this time I had seen no literature on the subject excect Dr. Clymer's article in Aitken's Practice.

Strictest regimen and a large curtailment of the bill of fare was enjoined. An effort was made to tone the nervous system by the administration of bark, iron and strychnia; but Fowler's solution and regimen were the means in which I had most faith. Having no battery at hand, faradization was not tried. The patient made some improvement. He was able to ascend two or three steps; could stoop and again assume the erect posture by simply placing one hand upon the knee instead of climbing with the hands up the legs as you see Herbert, his younger brother, do. (See cut No. 2.)

The restrictions as to diet were disregarded, because the boy's insatiable appetite could not be curbed by indulgent parents and good-natured servants. The patient petulantly protested against taking remedial agents, and the parents yielding to him, treatment was discontinued after less than two months' trial. At this time the boy, now near ten years old weighed 120 pounds. Within three months of the time he came under my care he was sent, against my protest, to the Surgical Institute in this city, where he was put upon the rack and his enfeebled muscles exhausted by enforced exercise. A brace was strapped upon him for the correction of the spinal curvature which is, as before stated, voluntarily or intuitively assumed as a compensatory relief of the enfeebled dorsal and lumbar muscles. After spending near six months in the institute, he returned to his home almost deprived of the power of locomotion, and within a few weeks he took to his chair, from which he has not arisen unaided since. $\mathrm{He}$ has been unable to walk or even to stand since he was eleven years old. At thirteen years he weighed I 40 pounds, but since that time he has lost by atrophy what he had gained by hypertrophy. The gastrocnemii are in permanent contraction. The disease has progressed very slowly since he took to his chair. He has not been treated for this affection since his return from the institute in this city. The muscles of the arms, back and shoulders are atrophied and powerless; but he derives much comfort and some profit from the use of the muscles of the forearm and hand, which are still subject to his will and retain a degree of force. The grasp is feeble yet he writes a beautiful, uniform hand. The abdominal, intercostal and sphincter muscles, and those of the face, throat and diaphragm seem to be intact. His mind is clear, memory good. He stands fair in his classes at school and, though not unusually quick, he is, in mathematics, rather better than most of his associates in this department. He expresses an earnest desire to have the progress of the disease arrested at this stage, and says that if he could remain as he is life would be enjoyable rather than burdensome to him.

The second son of this family never had any perceptible symptoms of this disease. He began to walk at twenty-one months; was intellectually clear though not brilliant; was peculiarly reticent and old in his ways though active in movement. $\mathrm{He}$ had a severe attack of rheumatism, which came upon him suddenly, making him helpless, one day at school. Whether this attack meant anything more than rheumatism I cannot say; yet, in the light of subsequent developments in this family, the presumption is strong that the disease under discussion entered as an important element. Urinary tests, however, and the usual treatment demonstrated the correctness of the diagnosis of rheumatism. There were cardiac complications. His chest was his vulnerable point in the opinion of his parents and former physician, and I acquiesced in that opinion long before this illness. When the more violent symptoms of rheumatism subsided a pulmonary trouble, which I then regarded as tuberculosis, terminated his life at the age of nine years. I have since thought that the lung affection would not so soon have carried him off had not paralysis of the diaphragm entered as a factor; but this is an afterthought and somewhat in the nature of speculation.

The third child, a blooming girl of ten years, is sprightly, healthy and mentally bright. I have no fears of her being affected, with this disease for the reasons that there are no indications of it, and the disease is almost, if not entirely confined to the male sex. Yet it is more than probable that she will transmit the disease, as the transmission has, hitherto, always been through the maternal ancestors.

The fourth child, a son, Herbert $T$., is before you. (See fig. 2.) $\mathrm{He}$ walked at thirteen months. 
It is needless to say that he is progressing more rapidly in his decline with this terrible malady than did his elder brother. $\mathrm{He}$ is eight years old. You observe the attitude he is compelled to assume in order to maintain his equilibrium, and his shambling gait, peculiar in the pitching the feet forward with the toes lower than the heels, the latter being the beginning of an equinism produced by permanent shortening of the gastrocnemii and paralysis of the extensors. Your attention is invited to the size of his calves and to their firmness to the touch; myo-sclerosic paralysis is not a misnomer. Observe that the muscles of the thighs, arms and back are beginning to atrophy. This boy, aside from this disease, has always had excellent health, a sharp appetite and a good digestion.

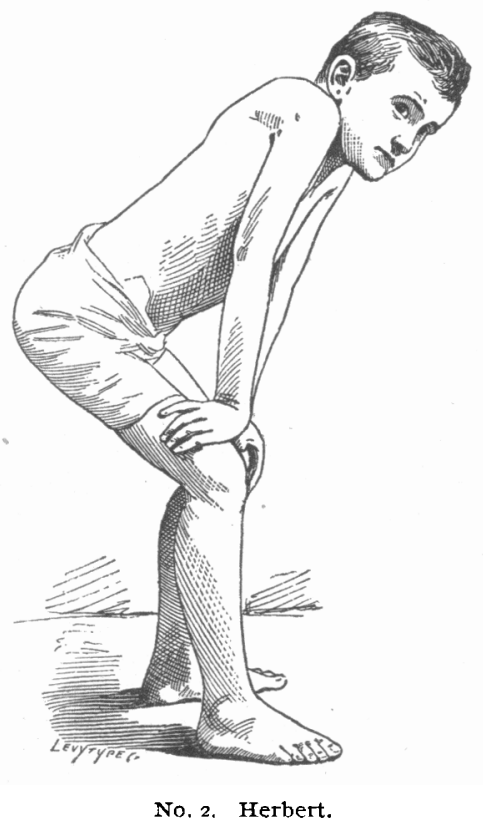

I desire to call your attention to his method of arising from the sitting or stooping posture. (See cut 2.) He will not permit one to lift him into the standing position, for the reason that he would fall forward if deprived of support before he was able to curve his spine into the peculiar saddle-back pose, with abdomen thrown forward and shoulders back. In order to attain the position given in cut No. 2, arising from the ground, he first gets upon hands and knees, then grasps his ankles, then climbs his legs with his hands. Having attained the position given in the cut the next act is to extend the knees, which is effected by bending forward and downward, so as to cast the center of gravity in front of the knees, the weight acting as the power at the hip joint, extending the knees without the use of the quadriceps extensor. To extend the hip joints the patient works his way up the thighs, placing his hands higher and higher until the erect posture is attained, the shoulders are cast back till the arms swing so far back that the hands drop back of the pelvis. This behavior in arising from the ground is striking and pathognomonic. Sir Charles Bell recognized it and declared that it is met in no other disease. Gowers and Hamilton are of the same opinion.

The youngest child, who is before you, a boy named Raymond $T$., is 3 years old. Has been healthy in the main. Had an attack of pneumonia last winter attended with great cerebral disturbance but no convulsions. He is clumsy, maintains the attitude of his brother Herbert in a less pronounced degree, and evidently will follow the pathway of his brothers, unless haply something can be done to avert this calamity.

The heads of these three boys are unusually large.

The eldest, Walter, æt. I 7 years, circumference of head $23 \frac{\mathrm{T}}{2}$ inches.

The third son, Herbert, æt. 8, circumference of head $21 / 1 / 8$ inches.

The youngest, Raymond, æt. 3 years, circumference of head $2 \mathrm{I} / 2$ inches.

So far as I have been able to learn there is no history of pseudo-hypertrophic muscular paralysis in the family of the mother of our patients. Her mother, who is still living and active, is now $7^{\circ}$ years of age.

The paternal grandfather, æt. 76 , is, undoubtedly, a subject of the disease, though he vindictively repudiates such an intimation, and, while he acknowledges that his back is weak and his arms and shoulders are not what they ought to be, he attributes his weakness and awkwardness to age, the effect of erysipelas and a fall received many years ago. From the best information I can get, the disease began to show itself in him after a traumatic lesion, and has progressed very slowly, though I cannot bring myself to believe that the disease originated in the traumatism, received after the age of 50 . I regard the tratmatism as the means of arousing the latent disease. About a month ago the old gentleman, after a ride of 22 miles, sat down to a very late dinner, and on attempting to arise from his chair, fell heavily to the floor, and was unable to arise for nearly one-half hour, declining help. This fall was followed by some fever and considerable mental agitation, a kind of talkative delirium for two or three days, after which he was, and is, as well in every respect as usual. The muscles of his back, thighs and arms are considerably atrophied, yet he is by no means so disabled as either of the grandsons shown you to-day.

There are two things unique in this case:

I. Development of the disease at an advanced age of perhaps 50 years.

2. Hereditary transmission through a son. Hitherto it has been only on the mother's side 
that the hereditary influence has been transmitted, while the disease develops almost invariably in males. Several brothers of the old gentleman died of phthisis pulmonalis; one died of some renal disease, probably diabetes mellitus, one sister had a slight paralytic seizure, but is fully recovered. All his brothers and sisters have lived to advanced age save one.

The boys shown you to-day have two uncles and an aunt on the father's side who are married and have children; but as yet none of these cousins, six in number, four males and two females, have shown symptoms of this disease, though two are fathers and two others have reached puberty. In conclusion, I ought to say, that there is not a male member of the grandfather's family or of his nephew's, with whom I am acquainted, whom I would regard as an active man, though they are energetic and of average strength.

HYSTERIA OF A GRAVE FORM IN THREE SUCCESSIVE PREGNANCIES. CASE.

Read before the Medical Society of the District of Columbia, June 6, 1888

BY ERNEST F. KING, A.M., M.D., OF WASHINGTON, D. c.

On Sunday, December 20, I885, I was sent for to see Mrs. X., æt. I9, then in the fourth month of her first pregnancy. I found her having sharp uterine pains every ten to fifteen minutes. She had been, as she declared, "unusually well" during the previous months, and could assign no cause for the threatened mischief. Upon the administration of opiates the pains ceased and there was no further trouble for about three weeks. At this time a train of symptoms began which continued throughout the pregnancy. Mrs. X. went to bed, refused food, seemingly did not recognize any of the family, threw herself from side to side, moaning constantly-in short, went through every manœuvre that an hysterical brain could contrive. This would continue for four or five days, and would be followed by an interval of about the same duration when the patient would appear like herself. Every expedient suggested for such cases was made trial of, but without permanent benefit. Tonics were administered throughout.

On Friday, June 4, labor began. The day before violent motions of the child were felt, which suddenly stopped. 'The os dilated slowly, the pains were infrequent and short. Sunday morning, the patient beginning to become exhausted, I applied the forceps and delivered a well-formed dead child. The mother almost immediately became as a different person. Within a week her form rounded out, color returned to her cheeks, and she declared that she " never felt better."

I saw Mrs. X. at intervals during the months following, and some time in November learned that she was again pregnant. She experienced no discomfort and appeared as usual. On February 15, I887, she went down town on a shopping expedition, and while lunching at a restaurant felt a sharp pain. She walked to her home, some nine blocks, and went to bed. I saw her within an hour after her return and found her having pains regularly. A foot protruded from the uterus, and in a short time the labor was completed. There were no unfavorable symptoms, and the following day a desire was expressed to go back and finish the lunch.

Both Mrs. X. and her husband were greatly disappointed at the result of these pregnancies, having experienced much pleasure in the anticipation of offspring. In April I learned that the third pregnancy dated from the first of March. On July 7 Mrs. X. came to my office complaining of slight pains at long intervals. I advised rest in bed and, when afterwards the pains increased in frequency, I ordered full doses of opium, which effectually controlled the difficulty. At this time began again the train of symptoms observed during the first pregnancy. There would be periods, lasting for days, of hysterical manifestations with intervals of quiet. There was a constant change of symptoms. No two attacks were exactly alike, though there were points of resemblance, such as taking no notice of what went on in the room, refusing to answer questions, complaining of her head, and refusing to touch food. However, food left in the room frequently disappeared.

Once there was complaint of numbness in one arm and inability to use the same. She was seen through a partially opened door to be fanning herself, using the paralyzed arm, but at the noise made in opening the door the arm dropped as though powerless. In October came a new trouble. Every few minutes the diaphragm would violently contract three or four times. Mrs. X. declared that the motions were those of the child. Aside from these movements she appeared natural. At this time Dr. Jos. Taber Johnson saw her with me.

In November there were two periods when she became violent and I feared she would harm herself or the child. She passed safely through these, however, and on December 5, 1887, she was safely delivered of a well developed male child. With the same elasticity before displayed she was immediately herself, grew strong rapidly, and is to-day in the best of spirits.

Briefly stated, Mrs. X. has been pregnant three times. Each time there has been no trouble up to the fourth month. At this period she miscarried once, and there was evidently danger of the same the other times. After the fourth month was completed the first and third pregnancies presented the same train of hysterical symptoms accompanied by weakness, pallor, loss of flesh and constipation. The urine, though carefully exam- 